\title{
Breast cancer biomarker (HER2-ECD) detection using a molecularly imprinted electrochemical sensor
}

\author{
João G. Pacheco*, Patrícia Rebelo, Maria Freitas, Henri P.A. Nouws, Cristina Delerue-Matos \\ REQUIMTE/LAQV, Instituto Superior de Engenharia do Porto, Politécnico do Porto, Rua Dr. António Bernardino de Almeida 431, 4200-072 Porto, Portugal
}

\author{
Keywords: \\ Breast cancer \\ Molecularly imprinted polymer \\ HER2 \\ Electrochemical sensor \\ Voltammetry
}

A B S T R A C T

The extracellular domain of the human epidermal growth factor receptor 2 (HER2-ECD) is a protein breast cancer biomarker. Its quantification in peripheral blood could provide an important contribution to diagnostics and patient follow-up. In this work an electrochemical molecularly imprinted polymer (MIP) sensor for the quantification of HER2-ECD was developed. The MIP was electropolymerized by cyclic voltammetry using a solution containing phenol and HER2-ECD on a screen-printed gold electrode (AuSPE). The sensor was characterized by cyclic voltammetry and electrochemical impedance spectroscopy. The analysis of HER2-ECD was performed by differential pulse voltammetry using $\left(\left[\mathrm{Fe}(\mathrm{CN})_{6}\right]^{3-/ 4-}\right.$ as redox probe. The linear range was established in the concentration interval from 10 to $70 \mathrm{ng} / \mathrm{mL}$ HER2-ECD, with a limit of detection of $1.6 \mathrm{ng} / \mathrm{L}$ and a limit of quantification of $5.2 \mathrm{ng} / \mathrm{mL}$. Through the analysis of other protein biomarkers, the MIP sensor was found to be selective. Furthermore, these proteins did not interfere in the analysis of the selected biomarker. The developed sensor was used for the analysis of spiked human serum samples, providing adequate recovery values and precise results. The outcomes of this study indicate that the developed MIP sensor could be useful in the noninvasive analysis of HER2-ECD in breast cancer patients.

\section{Introduction}

Breast cancer is the most common neoplasia among women [1]. Although breast cancer cases contribute to about $25 \%$ of cancer incidence worldwide, it is one of the leading cancer related mortality in women [2]. To date, an exponential increase of this oncological disease in women has been observed, and according to the data collected by the World Health Organization (WHO) in 2012, breast cancer was the second cause of cancer death in the more developed regions [3].

The effectiveness of mammography screening programs and the improvement in treatment and follow-up have been able to lower the mortality rate and thus, it is now lower than the incidence rate [4,5]. Therefore, early detection of cancer has a crucial role and is one of the major factors that contributes to increase not only the survival rates, but also to improve a successful clinical prognosis. Thus, a substantial reduction of effective treatment cost and time and an increase in the life expectancy can be attained [6,7]. Because of the inherent limitations of mammography screening, it should be complemented with additional clinical tests to avoid misdiagnosis or overdiagnosis [8]. This screening is usually not performed in young women ( $\leq 45$ years) because of its low sensitivity, leading to poor early diagnosis [9].

For early breast cancer detection and diagnosis, it is important to highlight that cellular changes at the protein level are considered potential tumor (bio)markers which complement screening methods, such as MRI, sonography and mammography $[10,11]$. A biomarker is defined by the National Cancer Institute as "a biological molecule found in blood, other body fluids, or tissues that is sign of a normal or abnormal process or of a condition disease" [12]. Thus, biomarkers allow the detection of specific diseases and the selection of effective interventions, improving the balance between benefit and harm of breast cancer screening [13]. Besides their detection in blood, breast cancer biomarkers can also be found in other biological fluids, including sputum and urine [14]. For the analysis of biological fluids non-invasive methodologies to revitalize early detection are required [7]. A simple non-invasive blood screening test could detect and monitor cancer progression and reduce the suffering of patients [15]. However, there are few blood-based biomarkers with clinical use in breast cancer detection [16].

The most reported breast cancer protein biomarkers are the Human Epidermal Growth Factor Receptor 2 (HER2), Cancer Antigen 15-3 (CA 15-3) and Carcinoembryonic Antigen (CEA) $[15,16]$. Of these proteins, HER2 is already established as a notably tissue marker [15], whose characterization is usually made in primary or metastatic tumors and has mainly been used as a target in immunotherapy $[17,18]$. Although

\footnotetext{
* Corresponding author.

E-mail address: jpgpa@isep.ipp.pt (J.G. Pacheco).
} 
this treatment is only effective in patients with an excess of receptor levels [14]. The protein has three domains: an extracellular domain (ECD) with similarities to other EGFRs, a short hydrophobic transmembrane region and an intracellular domain with tyrosine kinase activity. The ECD can be cleaved from the cell surface by matrix metalloproteases generating soluble truncated HER2 molecules, whose concentration can be measured in the serum fraction of the blood [19].

Currently, the established diagnostic tests to determine the expression of HER2 are based on invasive methods such as biopsies, using immunohistochemistry (IHC) and fluorescent in situ hybridization (FISH) methods $[19,20]$. However, both IHC and FISH techniques are limited to semiquantitative results, and are expensive and complex procedures, that are time consuming and require specially trained personnel to carry out the multi-step procedures $[20,21]$ and a highquality tissue sample [22,23].

The detection of HER2-ECD in blood or serum is not a routine practice [15]. However, besides its diagnostic importance, this biomarker can be a prognostic factor, with better results than tissue biopsy analysis [24,25]. More importantly, the protein level measurement has the potential of monitoring the course of the disease and the response of patients to treatment [14]. Considering that HER2-ECD in serum is generally quantified using an enzyme-linked immunosorbent assay (ELISA) and that the approved cut-off concentration is $15 \mathrm{ng} / \mathrm{mL}$, ELISA assays are not sufficiently sensitive in the prognostic detection. This is then susceptible to produce false results, highlighting the need for the development of a convenient, cost-effective and ultrasensitive method that minimizes the disadvantages of conventional methodologies $[15,26]$.

Electrochemical (bio)sensors have attracted considerable interest because of their particular properties such as high sensitivity and selectivity. These sensors are easy to use, provide fast responses and are cheap, disposable and capable of multi-analyte testing [8,21,27]. Among the several strategies to increase the selectivity of electrochemical sensors, molecularly imprinted polymers (MIP) can be used. MIPs offer the ability to mimic the highly selective bio-recognition characteristics of enzymes and antibodies and have physical and chemical resistances to degrading external factors, which make them promising analytical tools for the construction of biomimetic recognition systems $[27,28]$. Besides the success in the imprinting of small molecules, the imprinting of macromolecules (such as proteins) is in constant development, however it has some inherent difficulties, including size, conformation flexibility and solubility [29,30]. Electropolymerization of functional electroactive monomers directly on the transducer surface has proven to be a good option for protein imprinting because it allows polymerization in aqueous solutions, easy control and production of thin polymeric films. In this process the selected functional monomers are polymerized around the template $[31,32]$. Recently electrochemical MIP-based sensors have been applied as promising tools for early breast cancer detection. In a previous work developed by our team [33] a MIP-sensor for the detection of the protein breast cancer biomarker CA 15-3 was constructed based on direct surface imprinting of the protein, using 2-aminophenol as the monomer, on a screen-printed gold electrode (AuSPE). The detection limit of this sensor was $1.5 \mathrm{U} \mathrm{mL}^{-1}$ which is well below the used cut-off value in clinical practice for this biomarker $\left(25 \mathrm{U} \mathrm{mL}^{-1}\right)$.

In the present study a selective voltammetric MIP-sensor for the determination of HER2-ECD was developed. The imprinting of the cancer biomarker on AuSPE was performed by electropolymerization of a solution containing phenol (monomer) and HER2-ECD. The applicability of the sensor was tested by analyzing spiked human serum samples.

\section{Experimental}

\subsection{Reagents}

Recombinant HER2-ECD was obtained from Sino Biological Inc. Working solutions of HER2-ECD were prepared daily in phosphate buffer (0.1 M, pH 7.4) and stored at $4{ }^{\circ} \mathrm{C}$. Human serum (from male $\mathrm{AB}$ plasma) was obtained from Sigma-Aldrich. For interference studies, CA 15-3, obtained from MyBioSource, and Cystatin C, obtained from R\&D Systems were used.

Phenol ( $>99.5 \%$ ) and acetic acid ( $\geq 99.5 \%$ ) were purchased from Merck and Sodium dodecyl sulphate (SDS) from Panreac. Other commercially available reagents were used without further purification. Ultra-pure water (resistivity $=18.2 \mathrm{M} \Omega . \mathrm{cm}$ ) obtained from a Millipore (Simplicity 185) water purification system was used throughout the work. The phosphate buffer $\left(0.1 \mathrm{M}, \mathrm{pH}\right.$ 7.4) was prepared with $\mathrm{KH}_{2} \mathrm{PO}_{4}$ and $\mathrm{K}_{2} \mathrm{HPO}_{4}$ (Riedel-de-Haën).

\subsection{Apparatus}

Electrochemical measurements (cyclic voltammetry (CV) and differential pulse voltammetry (DPV)) were performed using a Metrohm Autolab PGSTAT 204 potentiostat/galvanostat controlled by NOVA 1.10 software. Electrochemical impedance spectroscopy (EIS) was performed using a Metrohm Autolab PGSTAT $128 \mathrm{~N}$ potentiostat/galvanostat controlled by NOVA 1.6 software. Screen-printed gold electrodes (Dropsens, DRP C223 AT) composed of gold working $(\mathrm{d}=1.6 \mathrm{~mm})$ and auxiliary electrodes, and a silver pseudo reference electrode were used. The specific connector (DRP-CAC) to interface the AuSPE and the potentiostat/galvanostat was supplied by DropSens.

\subsection{Sensor fabrication}

The stepwise construction process is illustrated in Fig. 1. Prior to their use the AuSPEs were rinsed with distilled water and activated with $0.1 \mathrm{M} \mathrm{H}_{2} \mathrm{SO}_{4}$ by $\mathrm{CV}$ (potential range: $-0.2 \mathrm{~V}$ to $+1.3 \mathrm{~V}$, scan rate: $100 \mathrm{mV} / \mathrm{s}$ ).

In the optimized construction of the MIP-sensor, $40 \mu \mathrm{L}$ of the polymerization solution ( $20 \mathrm{mM}$ phenol, $15 \mu \mathrm{g} / \mathrm{mL}$ HER2-ECD in phosphate buffer) was placed on the AuSPE and electropolymerization was carried out by $\mathrm{CV}$ in the potential range between $0.2 \mathrm{~V}$ and $+1.0 \mathrm{~V}$ at a scan rate of $100 \mathrm{mV} / \mathrm{s}$, during 20 cycles. A non-imprinted polymer electrode (NIP) was prepared using the same experimental conditions but excluding HER2-ECD from the polymerization solution. The electrodes were then rinsed with ultra-pure water and $40 \mu \mathrm{L}$ of an SDS $(0.5 \%)$ and acetic acid (0.5\%) solution was placed on the sensor surface for $30 \mathrm{~min}$. After this step, ultra-pure water was placed on the sensor for $10 \mathrm{~min}$, followed by phosphate buffer for an additional $5 \mathrm{~min}$. In this process, HER2-ECD is extracted from the polymeric films and cavities are formed that are complimentary to the protein's shape, size and functionality.

\subsection{Electrochemical detection}

The interactions between HER2-ECD and the MIP and NIP were indirectly measured using $\left[\mathrm{Fe}(\mathrm{CN})_{6}\right]^{3-/ 4-}(2 \mathrm{mM}$ in $0.1 \mathrm{M}$ phosphate buffer, $\mathrm{pH}$ 7.4) as redox probe. CV, DPV and EIS were used to characterize the sensors in the different optimization and construction steps. In the optimized assay to detect the breast cancer protein, the sensors were incubated with $20 \mu \mathrm{L}$ of a HER2-ECD solution during $7 \mathrm{~min}$ and then, between each protein incubation, washed with ultra-pure water and dried. The signal was recorded using $\mathrm{CV}(-0.1 \mathrm{~V}$ to $+0.6 \mathrm{~V}$ at a scan rate of $50 \mathrm{mV} / \mathrm{s})$ and DPV $(-0.2 \mathrm{~V}$ to $+0.8 \mathrm{~V}$ using a pulse amplitude of $25 \mathrm{mV}$ ). In the EIS measurements, a sinusoidal signal with a $10-\mathrm{mV}$ amplitude and a potential of $+0.2 \mathrm{~V}$ was applied (frequency range between 0.1 and $10,000 \mathrm{~Hz}$ with 50 frequencies distributed 


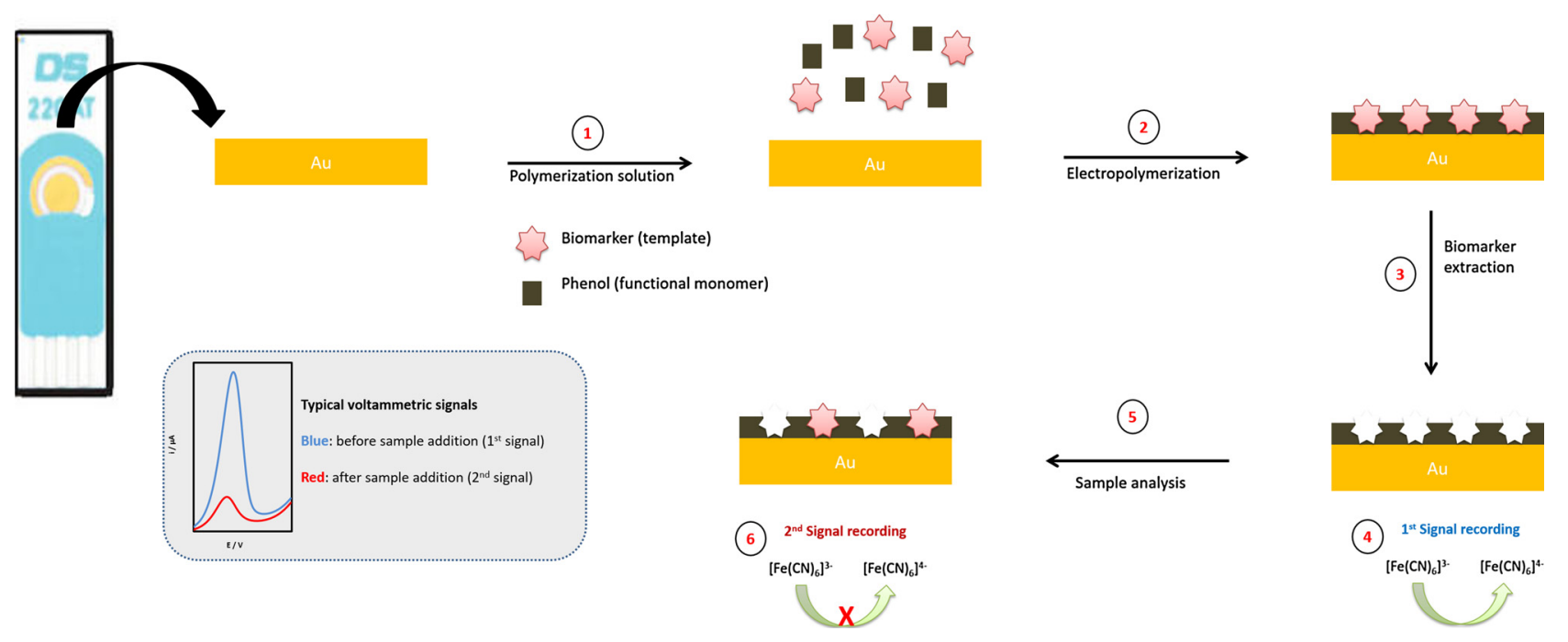

Fig. 1. Schematic illustration of the construction and operation of the MIP/AuSPE.

logarithmically). Randles equivalent electrical circuit was used as a model by fitting the Nyquist plot as experimental EIS data. All measurements were performed at room temperature.

\subsection{Sample preparation}

The human serum was first diluted to $50 \%$ with $0.1 \mathrm{M}$ phosphate buffer ( $\mathrm{pH}$ 7.4), and then spiked with different HER2-ECD concentrations and analysed without further treatment. The electrochemical measurements were performed according to the above-mentioned conditions.

\section{Results and discussion}

\subsection{MIP sensor preparation}

In this work, the molecular imprinting of HER2-ECD was performed by electropolymerization of a solution containing $20 \mathrm{mM}$ phenol and $15 \mu \mathrm{g} / \mathrm{mL}$ HER2-ECD in phosphate buffer ( $\mathrm{pH}$ 7.4) on the surface of AuSPEs. Electropolymerization was performed by $20 \mathrm{CV}$ scans between -0.2 and $+1.0 \mathrm{~V}$ (Fig. 2A), forming a polyphenol film with entrapped HER2-ECD molecules. The typical irreversible redox process of phenol was observed and an increase of the number of scans reduces the oxidation current intensity, indicating that the amount of polymer formed on the electrode surface increases because polyphenol is a non-conducting polymer that hinders electron transfer to the electrode surface. A NIP electrode was also prepared using the same conditions, but without the inclusion of HER2-ECD in the polymerization solution (Fig. 2B). As expected, differences between the film growths of the NIP and MIP were observed (Fig. 2C). In the first polymerization cycle the oxidation peak current intensity observed in the MIP process was lower than the one observed in the NIP process. This is mainly due to the interaction between HER2-ECD and phenol.

After the preparation of the polymeric film, a $2 \mathrm{mM}\left[\mathrm{Fe}(\mathrm{CN})_{6}\right]^{3-/ 4-}$ solution was analysed by DPV with the NIP and MIP sensors. As can be observed in Fig. 3 there is a significant difference between the signals obtained by both sensors. The oxidation peak current intensity of the redox probe obtained with the NIP was higher than the peak current for and MIP after polymerization. There is a major block in the signal of MIP. This result can be related to the entrapment of the HER2-ECD molecules. After the polymerization step the HER2-ECD molecules were removed from the MIP to assure that the binding cavities complementary to the molecular shape, size and functionality of HER2-ECD inside the polymeric film are created. The extraction conditions were optimised using the following extraction solutions: water, hydrochloric acid $(0.1 \mathrm{M})$ and methanol (50:50, v/v) mixture, guanidine (0.5 M), SDS $(0.5 \%)$ and acetic acid (0.5\%). Furthermore, the extraction time $(30,60$ and $90 \mathrm{~min}$ ) was also studied. It was found that the most adequate extraction procedure was achieved using an SDS $(0.5 \%)$ and acetic acid $(0.5 \%)$ solution during $30 \mathrm{~min}$. After extraction, a $2 \mathrm{mM}\left[\mathrm{Fe}(\mathrm{CN})_{6}\right]^{3-/}$ ${ }^{4-}$ solution was again analysed by DPV. As expected, the obtained peak current intensity increased when compared to the peak current intensity obtained after polymerization (Fig. 3), indicating the efficient removal of the HER2-ECD molecule template and the formation of the
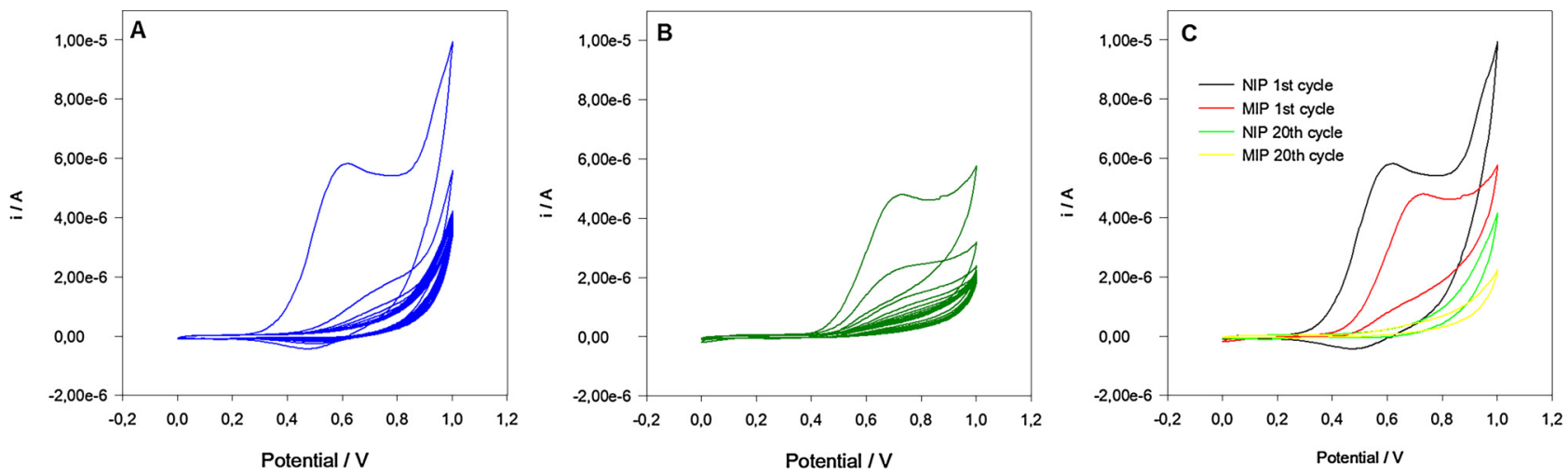

Fig. 2. CV voltammograms recorded during the electropolymerization on the AuSPE of (A) the MIP (20 mM phenol and $15 \mu \mathrm{g} / \mathrm{mL} \mathrm{HER} 2$-ECD, in $0.1 \mathrm{M}$ phosphate buffer pH 7.4 (20 cycles)), (B) NIP and (C) the NIP and MIP ( $1^{\text {st }}$ and $20^{\text {th }}$ scan). 


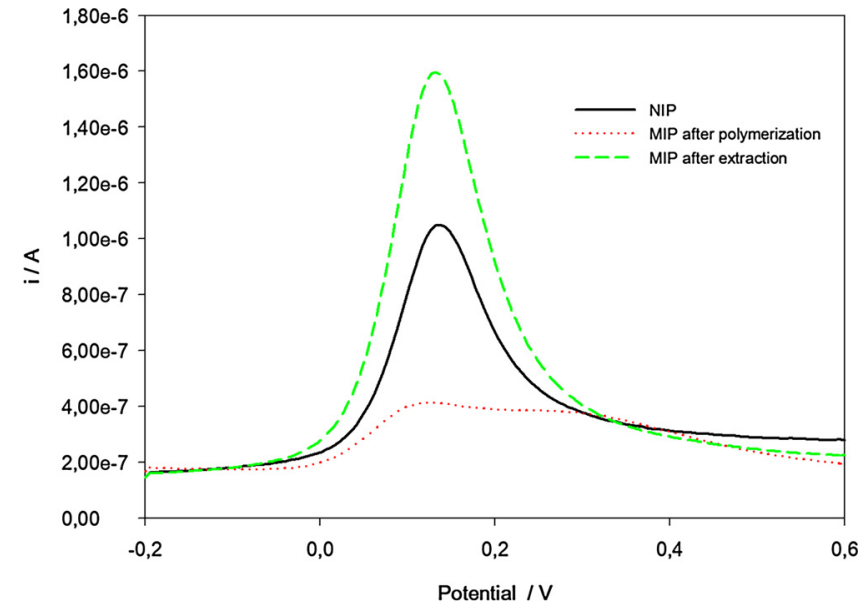

Fig. 3. DPV voltammograms of $2 \mathrm{mM}\left[\mathrm{Fe}(\mathrm{CN})_{6}\right]^{3-/ 4-}$ (in $0.1 \mathrm{M}$ phosphate buffer, pH 7.4) of NIP, MIP sensor after polymerization and MIP after the extraction of HER2-ECD.

specific cavities in the film.

\subsection{Optimization of polymerization conditions}

The electropolymerization process was optimised to obtain the highest signal for the redox probe in the DPV analysis. The following parameters of the process were studied: the number of CV cycles and the phenol and HER2-ECD concentrations (Fig. 4). The results are presented as the difference $\left(\Delta \mathrm{i}_{\mathrm{p}}\right)$ between the peak current intensity after the initial extraction of HER2-ECD and the peak current intensity after the subsequent incubation with HER2-ECD.

In electropolymerization it is possible to control the polymer thickness by controlling the number of potential cycles. Therefore, different number of CV cycles were tested (10, 20, 30 and 40) (Fig. 3A). As can be seen in Fig. $4 \mathrm{~A}$, the $\Delta \mathbf{i}_{\mathrm{p}}$ increased from 10 to 20 cycles, followed by a decrease from 20 to 40 cycles. This decrease is due to the formation of a thicker (non-conductive) polymer which hinders electron transfer and/or diffusion of the redox probe to the electrode surface, leading to lower $\Delta \mathrm{i}_{\mathrm{p}}$ values. For this reason, 20 polymerization cycles were chosen for the subsequent optimization steps.

Different concentrations of the monomer (phenol) in the polymerization solution were tested (1.0, 2.5, 5.0, 10 and $20 \mathrm{mM}$ ) (Fig. 4B): a continuous decrease of $\Delta \mathrm{i}_{\mathrm{p}}$ between 1.0 and $5.0 \mathrm{mM}$ and a continuous, but less accentuated, increase of $\Delta \mathrm{i}_{\mathrm{p}}$ between 5.0 and $20 \mathrm{mM}$ were observed. Because only a slight increase of $\Delta \mathrm{i}_{\mathrm{p}}$ between 10 and $20 \mathrm{mM}$ of phenol was seen, higher phenol concentrations were not tested and $20 \mathrm{mM}$ was chosen for further studies.

The optimal concentration of HER2-ECD in the polymerization solution was found to be $15 \mu \mathrm{g} / \mathrm{mL}$ (Fig. 3C): an increase of $\Delta \mathrm{i}_{\mathrm{p}}$ between 3 and $15 \mu \mathrm{g} / \mathrm{mL}$ was recorded, after which $\Delta \mathrm{i}_{\mathrm{p}}$ decreased. For the lower concentrations, lower amounts of the protein were entrapped in polymer, leading to less cavities and lower $\Delta \mathrm{i}_{\mathrm{p}}$ values. On the other hand, when the concentration was higher than $15 \mu \mathrm{g} / \mathrm{mL}$ the $\Delta \mathrm{i}_{\mathrm{p}}$ value decreased, which was probably due to the difficulty of extracting the protein from the polymer matrix, which also led to a lower number of formed cavities and a lower $\Delta \mathrm{i}_{\mathrm{p}}$ value.

After extraction, the inclusion of HER2-ECD in the MIP is obviously influenced by the incubation time. Therefore, the incubation time as also tested. It was found that $7 \mathrm{~min}$ incubation period was provided higher $\Delta \mathrm{i}_{\mathrm{p}}$ values.

\subsection{Characterization of the NIP- and MIP sensors}

Throughout the construction processes the sensors were characterised by $\mathrm{CV}$ and EIS using $2 \mathrm{mM}\left[\mathrm{Fe}(\mathrm{CN})_{6}\right]^{3-/ 4-}$. The results obtained with the bare electrode and the modified electrodes are shown in Fig. 5. With the bare gold electrode, a typical CV voltammogram of the redox probe was obtained, observing its well-defined reversible redox peaks. After polymerization, an expected decrease of the current response was registered with the NIP-AuSPE and MIP-AuSPE, which is characteristic for a passivated electrode surface. However, with the MIP-AuSPE the peak current intensities were slightly higher than the ones obtained with the NIP-AuSPE. This is probably due to the entrapment of protein in the polymeric film. After extraction, when the HER2-ECD molecules were removed from the MIP, the $i_{p}$ increased because of the unoccupied cavities that enhance the diffusion of $[\mathrm{Fe}$ $\left.(\mathrm{CN})_{6}\right]^{3-/ 4-}$ to the electrode surface and promote its redox behaviour, confirming the efficient removal of the template and the effectiveness of the MIP. When the MIP-AuSPE was incubated with an HER2-ECD solution, for $7 \mathrm{~min}$, the $i_{p}$ once again decreased. This indicates that HER2ECD occupied some of the previously formed cavities, preventing the diffusion and the redox reaction of $\left[\mathrm{Fe}(\mathrm{CN})_{6}\right]^{3-/ 4-}$. This also proves the ability of the MIP-sensor to incorporate HER2-ECD molecules after incubation.

Similar behaviours were observed in the EIS analyses. The semicircle of the Nyquist diagram for higher frequencies corresponds to the electron transfer process while the linear part of the lower frequency corresponds to diffusion. In Fig. 5 it can be observed a diffusion limited process with fast electron transfer kinetics for the bare AuSPE. As expected, after polymerization there was a high increase of the impedance of NIP and MIP and the surface was highly resistant to electron transfer due to the formation of the non-conducting polymer films. For MIP the surface is more resistant than NIP which can be explained by the entrapment of the protein. After protein extraction a high decrease of the impedance was observed due to the formation of cavities and then improving the diffusion of $\left[\mathrm{Fe}(\mathrm{CN})_{6}\right]^{3-/ 4-}$ through the polymer which facilitates the electron transfer electrons. Finally, after the incubation of
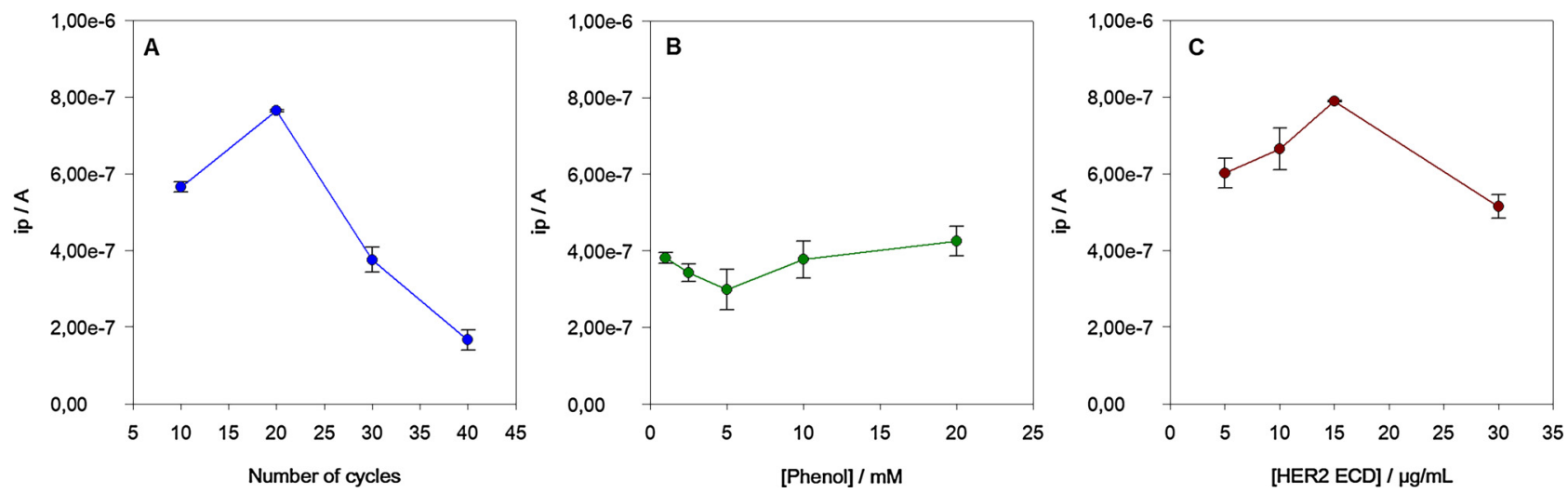

Fig. 4. Results obtained in the optimization of the polymerization process. (A) Number of CV cycles; (B) phenol concentration; and (C) HER2-ECD concentration. 


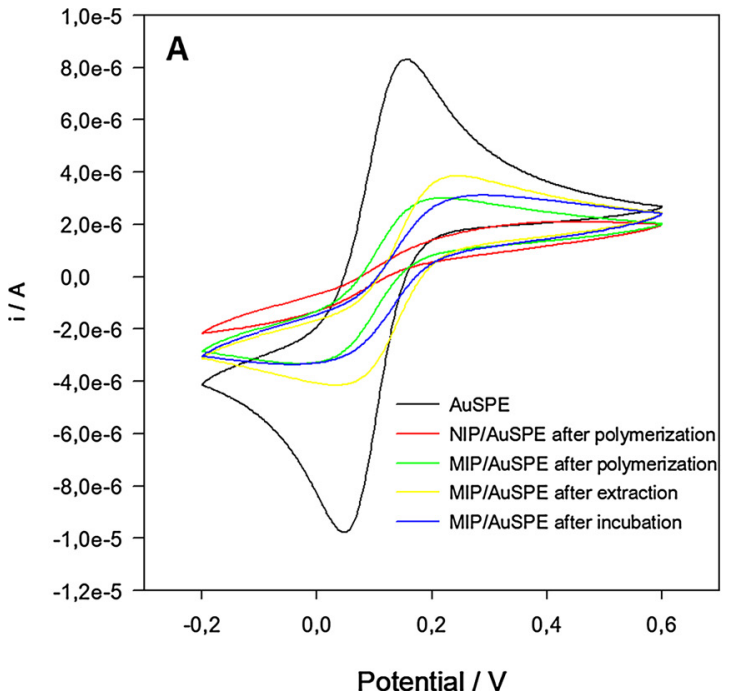

Fig. 5. Characterization of the step by step construction of the MIP/AuSPE sensor. (A) CV voltammograms and (B) EIS Nyquist diagrams in $\left.2 \mathrm{mM}\left[\mathrm{Fe}(\mathrm{CN})_{6}\right)\right]^{3-/ 4-}$ and $0.1 \mathrm{M}$ phosphate buffer $\mathrm{pH} 7$.

the protein an increase of the semicircle as registered. This indicates the ability of the MIP sensor to rebind to the protein.

\subsection{Analytical response}

Under the optimized conditions, the relationship between $\Delta \mathrm{i}_{\mathrm{p}}$ and HER2-ECD concentration was evaluated in the range of $10-70 \mathrm{ng} / \mathrm{mL}$ using the MIP-AuSPE (Fig. 6). A linear relationship was found between 10 and $70 \mathrm{ng} / \mathrm{mL}$ and the linear regression equation was: $\Delta \mathrm{i}_{\mathrm{p}}$ (A) $=1.259 \times 10^{-8} \quad[$ HER2-ECD $] \quad(\mathrm{ng} / \mathrm{mL})+1.490 \times 10^{-8}$ ( $\mathrm{R}=0.997$ ). The limits of detection (LOD) and quantification (LOQ) were $1.6 \mathrm{ng} / \mathrm{ml}$ and $5.2 \mathrm{ng} / \mathrm{mL}$, respectively. These limits were calculated using the following equations: $\mathrm{LOD}=3 \mathrm{~s} / \mathrm{m}$ and LOQ $=10 \mathrm{~s} / \mathrm{m}$, where "s" is the standard deviation of the intercept and " $\mathrm{m}$ " is the slope of the calibration line.

The intra-day and inter-electrode precision was evaluated by analyzing 7 HER2-ECD concentrations in the linear range, obtaining an average relative standard deviation of $15 \%$.

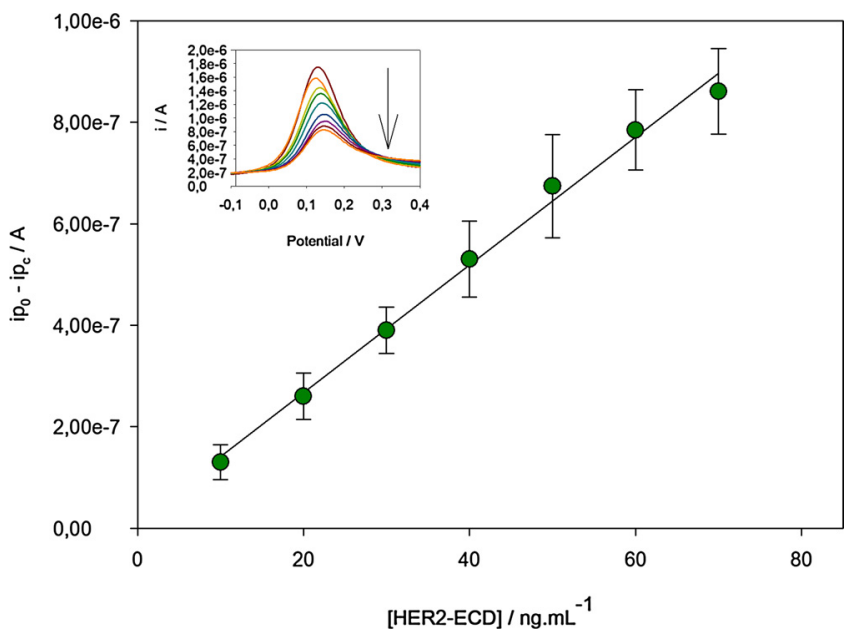

Fig. 6. Variation of the peak current intensity for MIP sensor with the concentration and DPV voltammograms obtained for MIP sensor after incubation with different protein concentrations in the range $10-70 \mathrm{ng} / \mathrm{mL}$. i $\mathrm{p}_{0}$ is the peak current before incubation, $\mathrm{ip}_{\mathrm{c}}$ is the peak current after incubation in different protein concentrations.

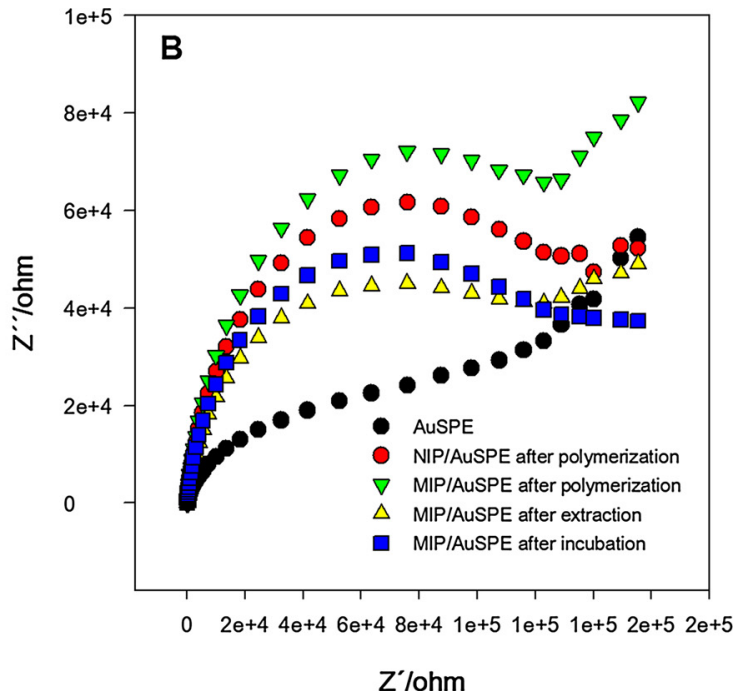

\subsection{Selectivity studies}

To verify the selectivity of the sensor, other serum proteins were analysed with the sensor: CA 15-3 (a breast cancer biomarker protein) and Cystatin C (an important renal biomarker protein). These proteins were chosen because they may also be present in serum samples. Concentrations of $30 \mathrm{U} / \mathrm{mL}$ for CA $15-3$ and $550 \mathrm{ng} / \mathrm{mL}$ for Cystatin C were used because these are respectively, the cut-off value for disease determination and the average value for healthy adults. In addition, parallel interference tests were carried out by mixing these proteins with HER2-ECD $(15 \mathrm{ng} / \mathrm{mL})$. All the solutions were prepared in human serum and both the NIP- and MIP-sensor were tested. As can be confirmed in Fig. 7 , the obtained $\Delta \mathrm{i}_{\mathrm{p}}$ for the MIP-sensor after incubation with HER2-ECD shows the highest value, demonstrating the effective imprinting process. When a CA 15-3 solution was analysed, the $\Delta i_{p}$ obtained with the MIP-sensor was about half $(51 \%)$ of the $\Delta \mathrm{i}_{\mathrm{p}}$ for HER2ECD and was identical to the NIP-sensor. For cystatin C, $\Delta \mathrm{i}_{\mathrm{p}}$ was only about a third (29\%) of the signal obtained when HER2-ECD was used. This indicates that the MIP-sensor is selective for HER2-ECD. Furthermore, the results obtained ( $95 \%$ of the original $\Delta \mathrm{i}_{\mathrm{p}}$ ) when HER2-ECD is incubated simultaneously with the other proteins show that these proteins do not interfere in the analysis.

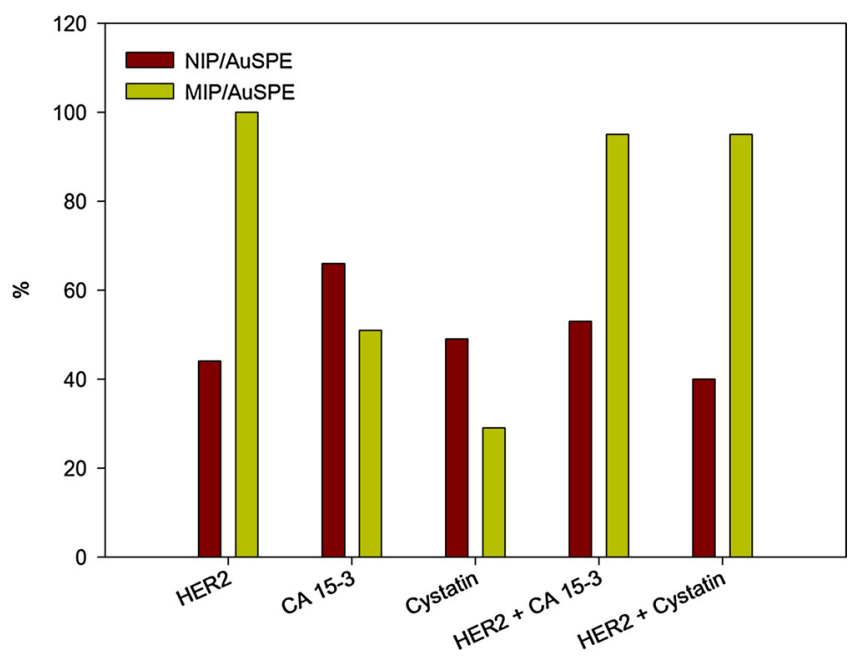

Fig. 7. Selectivity and interference studies. 
Table 1

Results of the determination of HER2-ECD in spiked human serum samples.

\begin{tabular}{llll}
\hline Added $(\mathrm{ng} / \mathrm{mL})$ & Found $(\mathrm{ng} / \mathrm{mL})$ & Recovery $(\%)$ & RSD (\%) \\
\hline 10 & 8.95 & 89.5 & 7.11 \\
30 & 27.1 & 90.2 & 10.2 \\
50 & 40.3 & 80.6 & 4.56 \\
\hline
\end{tabular}

\subsection{Detection of HER2-ECD breast cancer protein in biological samples}

To validate the application of the MIP-sensor for HER2-ECD detection and to evaluate the possibility for practical and clinical applications, the sensor was tested using human serum samples. The samples were spiked with three different protein concentrations $(10,30$ and $50 \mathrm{ng} / \mathrm{mL}$ ) and the analyses were carried out using the standard addition method. The obtained recovery values (Table 1 ) were between 80 and $90 \%$ and the RSD values were less than $10.2 \%$, demonstrating that the MIP-sensor provides accurate and precise results.

\section{Conclusion}

A selective molecularly imprinted polymer sensor for the detection of the breast cancer biomarker HER2-ECD was developed in this work. The sensor showed a linear concentration range from 10 to $70 \mathrm{ng} / \mathrm{L}$, with a limit of detection of $1.6 \mathrm{ng} / \mathrm{L}$. This limit is well below the established cut-off value. The developed methodology provides a simple, easy-to-operate, economical and selective analysis. Furthermore, the results of the analysis of the biomarker in human serum as well as the possibility for fast detection and decentralized analysis, indicate that this MIP-sensor could be of great promise for early clinical control tests and patient follow-up.

\section{Acknowledgements}

Maria Freitas is grateful to FCT (Fundação para a Ciência e a Tecnologia) for her $\mathrm{PhD}$ grant (SFRH/BD/111942/2015). Patrícia Rebelo is grateful to FCT (Fundação para a Ciência e a Tecnologia) for her PhD grant (SFRH/BD/132384/2017). João Pacheco is grateful to FCT for his Postdoc. grant (SFRH/BPD/101419/2014), financed by POPH-QREN-Tipologia 4.1-Formação Avançada, subsidized by Fundo Social Europeu and Ministério da Ciência, Tecnologia e Ensino Superior. This work received financial support from the European Union (FEDER funds through COMPETE) and National Funds (FCT) through project UID/QUI/50006/2013.

\section{References}

[1] J. Ferlay, I. Soerjomataram, R. Dikshit, S. Eser, C. Mathers, M. Rebelo, et al., Cancer incidence and mortality worldwide: sources, methods and major patterns in GLOBOCAN 2012, Int. J. Cancer 136 (2015) E359-E386.

[2] L. Ottini, C. Capalbo, P. Rizzolo, V. Silvestri, G. Bronte, S. Rizzo, et al., HER2positive male breast cancer: an update, Breast Cancer 2 (2010) 45-58.

[3] World Health Organization, International Agency for Cancer Research, GLOBOCAN, 2012 (Accessed September 2017), http://globocan.iarc.fr/Default.aspx.

[4] E. Senkus, S. Kyriakides, F. Penault-Llorca, P. Poortmans, A. Thompson, S. Zackrisson, et al., Primary breast cancer: ESMO clinical practice guidelines for diagnosis, treatment and follow-up $\dagger$, Ann. Oncol. 24 (2013) vi7-vi23.

[5] R.L. Siegel, K.D. Miller, A. Jemal, Cancer statistics, 2016, CA. Cancer J. Clin. 66 (2016) 7-30.

[6] M. Emami, M. Shamsipur, R. Saber, R. Irajirad, An electrochemical immunosensor for detection of a breast cancer biomarker based on antiHER2-iron oxide nanoparticle bioconjugates, Analyst 139 (2014) 2858-2866.

[7] R. Etzioni, N. Urban, S. Ramsey, M. McIntosh, S. Schwartz, B. Reid, et al., The case for early detection, Nat. Rev. Cancer 3 (2003) 243.

[8] M.G. Marmot, D.G. Altman, D.A. Cameron, J.A. Dewar, S.G. Thompson, M. Wilcox, et al., The benefits and harms of breast cancer screening: an independent review: a report jointly commissioned by cancer research UK and the department of health (England) october 2012, Br. J. Cancer 108 (2013) 2205-2240.

[9] D.S. Salem, R.M. Kamal, S.M. Mansour, L.A. Salah, R. Wessam, Breast imaging in the young: the role of magnetic resonance imaging in breast cancer screening, diagnosis and follow-up, J. Thorac. Dis. 5 (2013) S9-S18.
[10] Molecular Pathology: A Practical Guide for the Surgical Pathologist and Cytopathologist, Cambridge University Press, Cambridge, 2015.

[11] S. Mittal, H. Kaur, N. Gautam, A.K. Mantha, Biosensors for breast cancer diagnosis: a review of bioreceptors, biotransducers and signal amplification strategies, Biosens. Bioelectron. 88 (2017) 217-231.

[12] M. Hasanzadeh, N. Shadjou, M. de la Guardia, Early stage screening of breast cancer using electrochemical biomarker detection, TrAC Trends Anal. Chem. 91 (2017) 67-76.

[13] F. Stracci, Cancer screenings, diagnostic technology evolution, and cancer control, in: M. Verma (Ed.), Cancer Epidemiology, Humana Press, Totowa, NJ, 2009, pp. 107-136

[14] E. Arkan, R. Saber, Z. Karimi, M. Shamsipur, A novel antibody-antigen based impedimetric immunosensor for low level detection of HER2 in serum samples of breast cancer patients via modification of a gold nanoparticles decorated multiwall carbon nanotube-ionic liquid electrode, Anal. Chim. Acta 874 (2015) 66-74.

[15] R.C.B. Marques, S. Viswanathan, H.P.A. Nouws, C. Delerue-Matos, M.B. González García, Electrochemical immunosensor for the analysis of the breast cancer biomarker HER2 ECD, Talanta 129 (2014) 594-599.

[16] A. Berghuis, H. Koffijberg, J. Prakash, L. Terstappen, M. IJzerman, Detecting bloodbased biomarkers in metastatic breast cancer: a systematic review of their current status and clinical utility, Int. J. Mol. Sci. 18 (2017) 363.

[17] B. Aktas, S. Kasimir-Bauer, V. Müller, W. Janni, T. Fehm, D. Wallwiener, et al., Comparison of the HER2, estrogen and progesterone receptor expression profile of primary tumor, metastases and circulating tumor cells in metastatic breast cancer patients, BMC Cancer 16 (2016) 522

[18] A. Milani, D. Sangiolo, F. Montemurro, M. Aglietta, G. Valabrega, Active immunotherapy in HER2 overexpressing breast cancer: current status and future perspectives, Ann. Oncol. 24 (2013) 1740-1748.

[19] C. Tsé, A.-S. Gauchez, W. Jacot, P.-J. Lamy, HER2 shedding and serum HER2 extracellular domain: biology and clinical utility in breast cancer, Cancer Treat. Rev. 38 (2012) 133-142.

[20] A. Tabasi, A. Noorbakhsh, E. Sharifi, Reduced graphene oxide-chitosan-aptamer interface as new platform for ultrasensitive detection of human epidermal growth factor receptor 2, Biosens. Bioelectron. 95 (2017) 117-123.

[21] J.T. Gohring, P.S. Dale, X. Fan, Detection of HER2 breast cancer biomarker using the opto-fluidic ring resonator biosensor, Sens. Actuators B: Chem. 146 (2010) 226-230.

[22] S. Hanash, A. Taguchi, Application of proteomics to cancer early detection, Cancer J. (Sudbury, Mass) 17 (2011) 423-428.

[23] S. Shukla, B.K. Singh, O.P. Pathania, M. Jain, Evaluation of HER2/neu oncoprotein in serum \& tissue samples of women with breast cancer, Indian J. Med. Res. 143 (2016) S52-S58.

[24] D. Di Gioia, M. Dresse, D. Mayr, D. Nagel, V. Heinemann, P. Stieber, Serum HER2 in combination with CA 15-3 as a parameter for prognosis in patients with early breast cancer, Clin. Chim. Acta 440 (2015) 16-22.

[25] L.N. Harris, V. Liotcheva, G. Broadwater, M.J. Ramirez, P. Maimonis, S. Anderson, et al., Comparison of methods of measuring HER-2 in metastatic breast cancer patients treated with high-dose chemotherapy, J. Clin. Oncol. 19 (2001) 1698-1706.

[26] L. Lam, N. McAndrew, M. Yee, T. Fu, J.C. Tchou, H. Zhang, Challenges in the clinical utility of the serum test for HER2 ECD, Biochim. Biophys. Acta (BBA) - Rev. Cancer 1826 (2012) 199-208.

[27] G. Selvolini, G. Marrazza, MIP-based sensors: promising new tools for cancer biomarker determination, Sensors (Basel, Switzerland) 17 (2017) 718.

[28] L. Chen, X. Wang, W. Lu, X. Wu, J. Li, Molecular imprinting: perspectives and applications, Chem. Soc. Rev. 45 (2016) 2137-2211.

[29] Y. Saylan, F. Yilmaz, E. Özgür, A. Derazshamshir, H. Yavuz, A. Denizli, Molecular imprinting of macromolecules for sensor applications, Sensors (Basel, Switzerland) 17 (2017) 898.

[30] M.J. Whitcombe, I. Chianella, L. Larcombe, S.A. Piletsky, J. Noble, R. Porter, et al., The rational development of molecularly imprinted polymer-based sensors for protein detection, Chem. Soc. Rev. 40 (2011) 1547-1571.

[31] J. Erdőssy, V. Horváth, A. Yarman, F.W. Scheller, R.E. Gyurcsányi, Electrosynthesized molecularly imprinted polymers for protein recognition, TrAC, Trends Anal. Chem. 79 (2016) 179-190.

[32] F. Lopes, J.G. Pacheco, P. Rebelo, C. Delerue-Matos, Molecularly imprinted electrochemical sensor prepared on a screen printed carbon electrode for naloxone detection, Sens. Actuators B: Chem. 243 (2017) 745-752.

[33] J.G. Pacheco, M.S.V. Silva, M. Freitas, H.P.A. Nouws, C. Delerue-Matos, Molecularly imprinted electrochemical sensor for the point-of-care detection of a breast cancer biomarker (CA 15-3), Sens. Actuators B: Chem. 256 (2018) 905-912. 